\title{
Melanin and Curls: Evaluation of Black Women Candidates - CORRIGENDUM
}

\author{
Danielle Casarez Lemi and Nadia E. Brown
}

https://doi.org/10.1017/rep.2019.18. Published online by Cambridge University Press, 29 July 2019

In the reference for Spellers et al. (2003) in the article by Lemi and Brown (2019), the lead author's name was misspelled. The reference should appear as follows.

Spellers, Regina E. 2003. “The Kink Factor: A Womanist Discourse Analysis of African-American Mother/daughter Perspectives on Negotiating Black Hair/body Politics." In Understanding African American Rhetoric: Classical Origins to Contemporary Innovations, eds. R.L. Jackson and E.B. Richardson. New York, NY: Routledge, 223-43.

The reference has been corrected in the article.

\section{Reference}

Lemi DC and Brown NE (2019) Melanin and Curls: Evaluation of Black Women Candidates. The Journal of Race, Ethnicity, and Politics 4 (2), 259-296. https://doi.org/10.1017/rep.2019.18.

Cite this article: Lemi DC, Brown NE (2022). Melanin and Curls: Evaluation of Black Women Candidates - CORRIGENDUM. The Journal of Race, Ethnicity, and Politics 7, 355-355. https://doi.org/10.1017/ rep. 2021.42

(c) The Author(s), 2022. Published by Cambridge University Press on behalf of The Race, Ethnicity, and Politics Section of the American Political Science Association 